\title{
DETERIORATION IN THE ACCURACY OF THE PULSAIR NON-CONTACT TONOMETER WITH USE: NEED FOR REGULAR CALIBRATION
}

\author{
P. L. ATKINSON ${ }^{1}$, P. K. WISHART ${ }^{1}$, J. N. JAMES ${ }^{2}$, S. A. VERNON ${ }^{2}$, F. REID ${ }^{3}$ \\ Liverpool, Nottingham and London
}

\begin{abstract}
SUMMARY
The Pulsair non-contact tonometer (Keeler Pulsair ${ }^{\mathrm{TM}}$ : Keeler UK) has been shown to be a versatile instrument particularly suitable for screening for raised intraocular pressure. Although demonstrated to be accurate initially when compared to the Goldmann applanation tonometer no study has examined its long-term accuracy. Comparisons of three Pulsair tonometers with different degrees of usage with the Goldmann tonometer are described. Measurements were obtained from 64, 116, and 223 eyes in three separate comparative studies. Correlation coefficients of between 0.78 and 0.90 were obtained, the least used instrument being significantly more accurate than the two more extensively used instruments. Taking the Goldmann tonometer as the standard tonometer, and the aim to detect intraocular pressures of greater than 21 $\mathrm{mmHg}$, sensitivities of $40 \%, 48 \%$, and $85 \%$ for the three Pulsair tonometers respectively were shown. The Pulsair tonometer appears liable to a long-term drift in accuracy with use, and we suggest that provision is made for the regular re-calibration of the instrument.
\end{abstract}

The Keeler Pulsair is a non-contact tonometer (NCT) used for measuring intraocular pressure (IOP). Its mode of action is to apply a ramped pulse of air to the cornea and measure the pressure required to flatten the cornea to a predetermined degree as assessed by the deviation of a beam of light detected by an array of photodetectors. ${ }^{1}$ It shares with older NCTs the advantages of lack of the need for topical anaesthesia, no mechanical contact with the eye, and an objective reading of the IOP, ${ }^{2}$ with the added benefits of portability and a better tolerated lower volume air puff.

Since its introduction the Pulsair NCT has been advo-

'St Paul's Eye Hospital, Liverpool, UK.

${ }^{2}$ Department of Ophthalmology, Queens Medical Centre, Nottingham, UK.

${ }^{3}$ Department of Public Health and Epidemiology, King's College School of Medicine and Dentistry, London, UK.

Correspondence to: Mr. P. K. Wishart, Glaucoma Unit, St Paul's Eye Hospital, Old Hall Street, Liverpool L3, UK. cated as a sensitive method of screening for raised IOP both in the community ${ }^{3}$ and in post-operative patients. ${ }^{4}$ The instrument is supplied factory calibrated, the calibration being based on comparisons with the Goldmann applanation tonometer (AT) where it achieved a high degree of accuracy with a correlation coefficient $(r)$ of up to 0.95 .' Subsequent studies ${ }^{5-7}$ have also shown the Pulsair tonometer to have good initial accuracy when compared to the Goldman AT. However, no study has assessed the long-term accuracy of the instrument. We separately compared three Pulsair tonometers of varying ages and degrees of usage to the Goldmann AT to assess their accuracy. We also evaluated the performance of each machine as a screening instrument on the basis of the results obtained.

\section{PATIENTS AND METHODS}

Three Pulsair NCTs were individually compared to the Goldmann AT in three separate studies. Machines A and B were studied at St Paul's Eye Hospital, Liverpool, and machine C was studied at the Queen's Medical Centre, Nottingham. Study patients were drawn randomly from the general ophthalmology outpatient departments and glaucoma clinics. Uncooperative patients or those with scarred corneas were excluded from the studies.

\section{Pulsair NCT}

All measurements were obtained from the seated patient by the same experienced operator for each study. All Pulsair NCT measurements were taken before using the Goldmann AT. Two methods were used to calculate the final IOP result, reflecting the methods in use at the time of the studies in the two centres. For machines A and B at least three readings were taken until three readings lay within 5 $\mathrm{mmHg}$ of each other. The mean of these three readings was taken as the IOP. For machine $\mathrm{C}$ the mean of four successive readings was taken as the IOP. If any reading exceeded $30 \mathrm{mmHg}$ a further set of measurements was taken with the machine set in the ' $30+$ ' mode, in accordance with the manufacturer's instructions. 
Table I. Comparison of number of eyes tested, mean IOP, correlation coef ficient and regression equation for each Pulsair NCT

\begin{tabular}{|c|c|c|c|c|c|}
\hline \multirow{2}{*}{$\begin{array}{l}\text { Pulsair } \\
\text { machine }\end{array}$} & \multirow{2}{*}{$\begin{array}{l}\text { No. of eyes } \\
\qquad(n)\end{array}$} & \multicolumn{2}{|c|}{ Mean IOP $(\mathrm{mmHg})[\mathrm{SD}]$} & \multirow{2}{*}{$\begin{array}{c}\text { Correlation } \\
\text { coeff. }(r)\end{array}$} & \multirow{2}{*}{$\begin{array}{c}\text { Regression } \\
\text { equation }\end{array}$} \\
\hline & & Pulsair NCT & Goldmann AT & & \\
\hline A & 64 & $\begin{array}{l}18.0 \\
{[6.6]}\end{array}$ & $\begin{array}{l}17.5 \\
{[6.4]}\end{array}$ & 0.90 & $y=0.93 x+1.67$ \\
\hline B & 223 & $\begin{array}{l}16.0 \\
{[4.3]}\end{array}$ & $\begin{array}{l}18.9 * \\
{[5.4]}\end{array}$ & 0.82 & $y=0.66 x+3.50$ \\
\hline $\mathrm{C}$ & 116 & $\begin{array}{l}16.9 \\
{[5.2]}\end{array}$ & $\begin{array}{l}18.7^{*} \\
{[5.2]}\end{array}$ & 0.78 & $y=0.71 x+3.54$ \\
\hline
\end{tabular}

$\mathrm{SD}=$ standard deviation

$*=$ difference in mean readings significant $p<0.01$ (Student's paired $t$-test).

\section{Goldmann AT}

In each study a second experienced operator recorded the IOP using a calibrated Haag-Streit AG Goldmann tonometer. The measurement was made within 3 minutes of the Pulsair NCT measurements with the patient remaining seated between measurement and following the instillation of oxybuprocaine $0.4 \%$ and fluorescein. The Goldmann AT operator was unaware of the Pulsair NCT results. It has been demonstrated that the Pulsair NCT has no significant effect on the IOP subsequently measured using the Goldmann AT.

\section{RESULTS}

The studies were performed over a two-month period.

At the time of the study Pulsair A was 20 months old and was the least used of all three machines, being used solely for measuring the IOP during examination under anaesthetic in the operating theatre.

Pulsair B was nine months old and had seen frequent and regular use in the outpatient department. This machine had been used to measure the IOP on something in the region of 1000 patients and had therefore been discharged approximately 4000 times. Pulsair C was 24 months old and had been used in a community screening
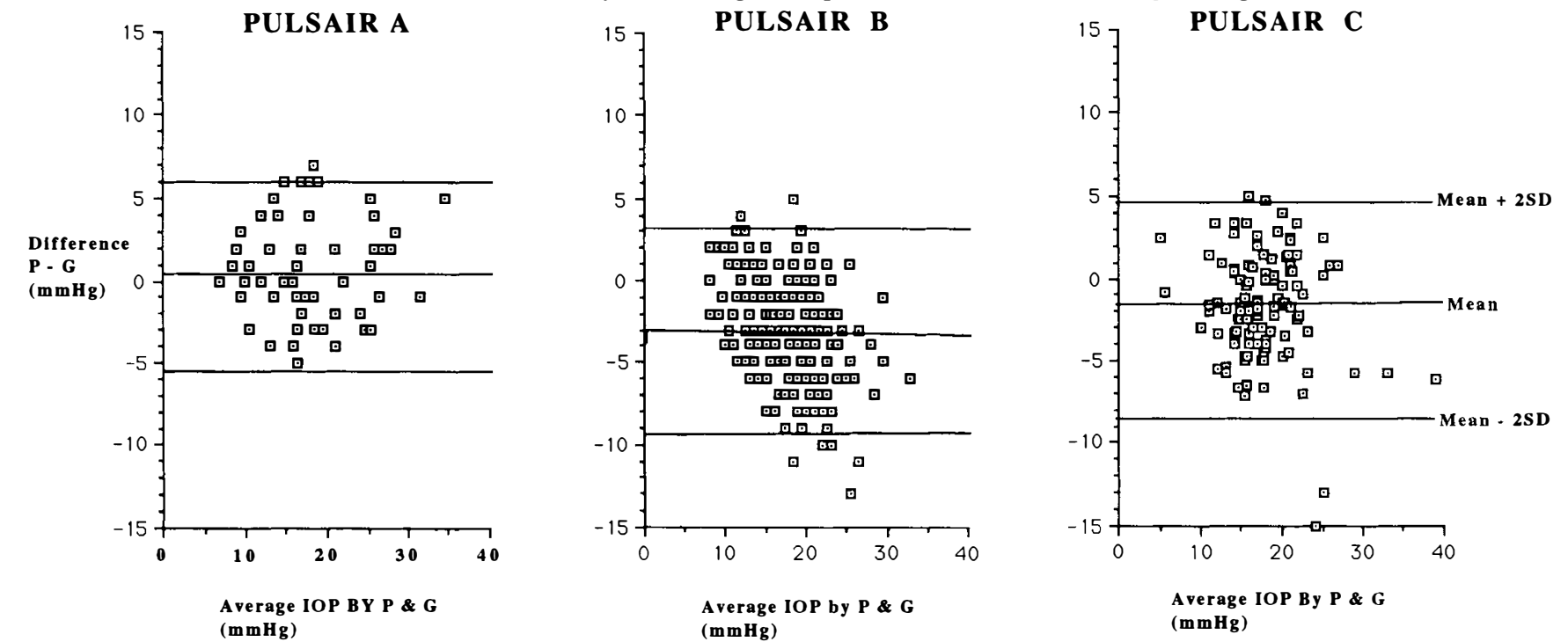

Fig. 1. The difference between Pulsair and Goldmann readings plotted against the average of that pair of readings. The middle horizontal line indicates the mean value of the differences with the range of two standard deviations above and below the mean difference shown by the upper and lower lines. Note some data points represent results from two or more eyes.

project $^{3}$ and an earlier comparison of the Pulsair NCT and the Goldmann $\mathrm{AT}^{4}$ as well as clinic use. It had discharged approximately 10000 pulses, and was the most used instrument.

From corresponding Pulsair and Goldmann readings a correlation coefficient $(r)$ was calculated for each machine. This describes the strength of the relationship between the Pulsair and Goldmann readings, a value of 1 indicating that one set of data is a perfect multiple of the other, and a value of zero indicating no relationship. The equation describing the straight line best fitting a scatter diagram plotting pairs of Pulsair-Goldmann readings was also determined (the linear regression analysis equation). Ideally, the slope of the line should be 1 with an intercept of zero. Table I shows a comparison of these results for the three machines. It also shows the mean, values of the Pulsair and Goldmann readings for each machine, with the difference between the means being statistically significant for the studies involving machines $\mathrm{B}$ and $\mathrm{C}$.

The correlation coefficient and linear regression equation are widely used when comparing the accuracy of tonometers, and have been calculated in this study to allow comparison with other studies. However, it has been shown that the use of these indices is not the most appropriate method of assessing the agreement of two devices 
Table II. The mean of the differences between Pulsair and Goldmann readings for each Pulsair NCT

\begin{tabular}{ccc}
\hline $\begin{array}{c}\text { Pulsair } \\
\text { machine }\end{array}$ & $\begin{array}{c}\text { Mean of differences } \\
\text { (Pulsair - Goldmann) } \\
\text { mmHg [SD] }\end{array}$ & $\begin{array}{c}\text { 95\% interval } \\
\text { for differences }\end{array}$ \\
\hline A & 0.53 & -5.4 to 6.5 \\
B & $12.97]$ & -9.1 to 3.3 \\
C & -2.92 & -8.4 to 4.7 \\
\hline
\end{tabular}

$\mathrm{SD}=$ standard deviation.

$95 \%$ interval $=$ the interval in which $95 \%$ of the differences lie.

indirectly measuring the same quantity. ${ }^{8}$ Figure 1 presents the data in the way suggested by Bland and Altman. ${ }^{8}$ For each Pulsair machine, the difference between the Pulsair and Goldmann readings for each pair of readings is plotted against the mean of that pair of readings. This demonstrates the range of the differences between the Pulsair and Goldmann readings and also whether these bear any clear relationship with the level of IOP being measured. For each Pulsair machine the mean of the differences is indicated together with the interval of two standard deviations above and below the mean. Approximately $95 \%$ of all points lie between these limits. It can be seen that for all the machines the range of differences is large although the means vary, Pulsair A having the mean nearest to zero. Table II shows the values of the mean and standard devia- tion of the differences for each machine, together with the interval within which $95 \%$ of the differences lie.

If it is taken from Fig. 1 that no strong relationship exists between the Pulsair-Goldmann differences and the level of IOP for any of the three machines, then it is valid to make statistical comparisons of the results for the three Pulsair machines. This assumes that there are no other differences between the three study populations which may affect the relative performance of the machines. Performing a two sample $t$-test to compare the mean differences for Pulsairs A and B, A and C, and B and C respectively, demonstrates that all three mean differences are significantly different from one another $(p<0.05$ corrected for carrying out multiple tests).

Figure 2 indicates the distribution of individual differences between the Pulsair and Goldmann readings for the three Pulsair NCTs showing the more heavily used Pulsair instruments (B and $\mathrm{C}$ ) to be under-reading compared to the Goldmann tonometer. In assessing the suitability of a tonometer as a screening instrument it is important to test the validity of its results when used in a screening role. Taking the Goldmann AT as the standard tonometer, and the aim to detect IOPs of greater than $21 \mathrm{mmHg}$, the sensitivity of the Pulsair NCT is given by the number of true positive cases detected (Goldmann and Pulsair IOP $>21$ $\mathrm{mmHg}$ ) divided by the total number of positive cases (Goldmann IOP $>21 \mathrm{mmHg}$ ). The specificity of the Pulsair NCT is given by the number of negative cases correctly identified (Goldmann and Pulsair IOP $<22 \mathrm{mmHg}$ )

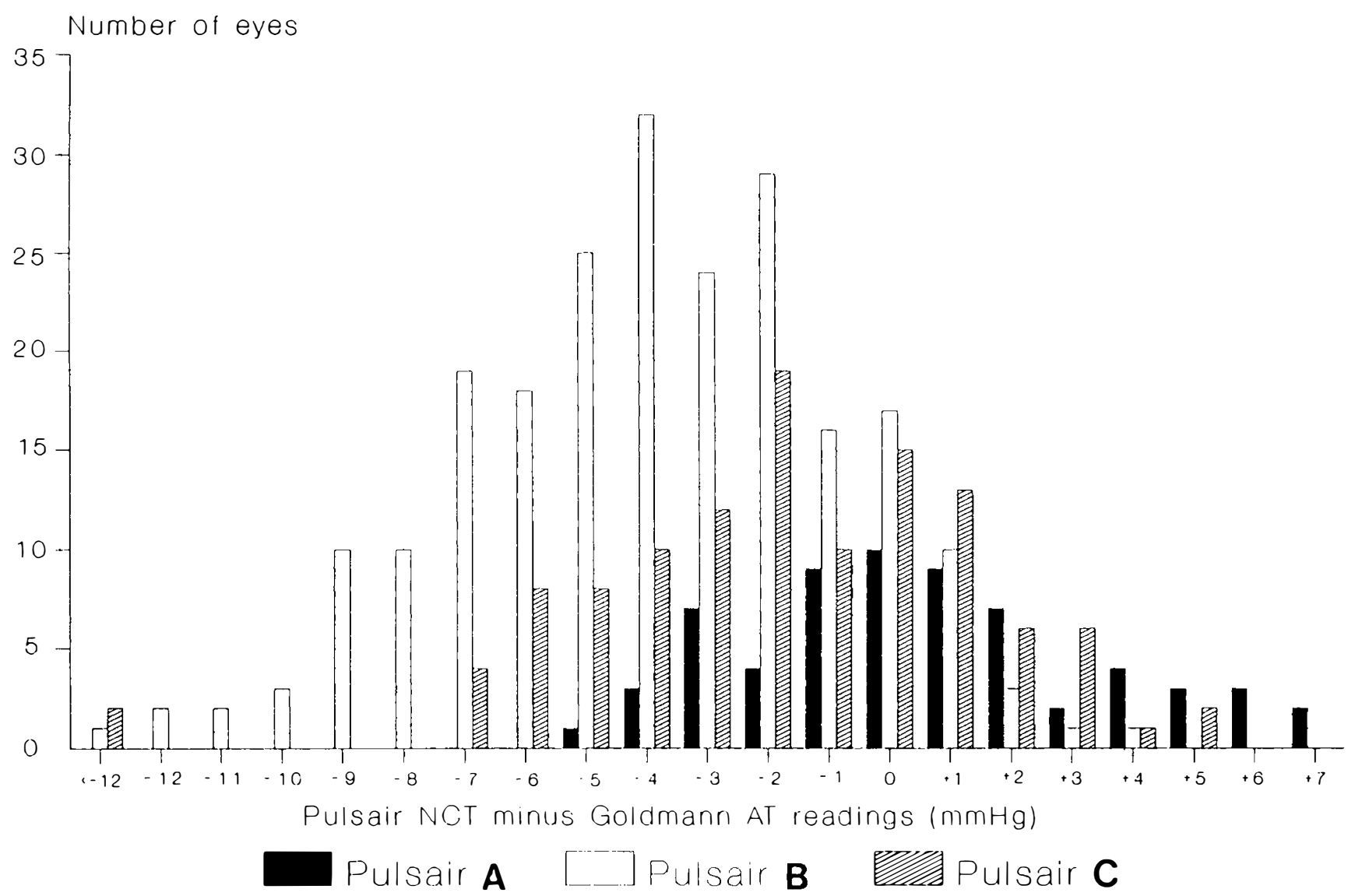

Fig. 2. Frequency histogram of Pulsair minus Goldmann readings for the three Pulsair NCTs. 
Table III. Sensitivity and specificity of the 3 Pulsair NCTs for detecting a Goldmann IOP $>21 \mathrm{mmHg}$ in each study population.

\begin{tabular}{cccc}
\hline $\begin{array}{c}\text { Pulsair } \\
\text { machine }\end{array}$ & $\begin{array}{c}\text { Proportion eyes with } \\
\text { Goldmann }>21 \mathrm{mmHg}\end{array}$ & Sensitivity & Specificity \\
\hline A & $20 / 64$ & $85 \%$ & $93 \%$ \\
B & $92 / 233$ & $40 \%$ & $95 \%$ \\
C & $21 / 116$ & $48 \%$ & $94 \%$ \\
\hline
\end{tabular}

divided by the total number of negative cases (Goldmann IOP $<22 \mathrm{mmHg}$ ). Table III shows these results for the three Pulsair NCTs and indicates the performance of each of the NCTs at screening for an IOP of greater than 21 $\mathrm{mmHg}$ in each of their study populations.

\section{DISCUSSION}

Our comparison of three Pulsair tonometers of different ages and degrees of usage to the Goldmann AT has shown a large variation in the accuracy of the Pulsair instruments. Results from the least used Pulsair NCT (machine A) showed an average difference between the Pulsair and Goldmann readings of $0.5 \mathrm{mmHg}$ with a good correlation with the Goldmann AT $(r=0.90)$. Results from the two more extensively used Pulsair NCTs (machines B and C) showed the Pulsair instruments to be under-reading the Goldmann AT by, on average, $2-3 \mathrm{mmHg}$, with less satisfactory correlation of readings with the Goldmann AT $(r=0.82$ and 0.78$)$. However, the range of differences between the Pulsair and Goldmann tonometers for a given IOP (Fig. 1) was large for all three machines and it is questionable whether this is clinically acceptable. It is of interest that when relatively new, Pulsair $\mathrm{C}$ had been compared to the Goldmann AT in a study of IOP measurement in postoperative eyes. ${ }^{4}$ In this study of 48 eyes the Pulsair NCT readings correlated well within the Goldmann AT $(r=0.92)$ with a regression equation of $y=1.19 x+0.88$ and a tendency to read higher than the Goldmann AT. Although this was a small study on a different group of patients it suggests that the accuracy of this machine has deteriorated, initially over-reading and now under-reading the Goldmann AT.

The ability of the Pulsair NCTs to screen for those eyes with a raised IOP also varied markedly between instruments. Taking as the aim the ability to detect those eyes with a Goldmann IOP greater than $21 \mathrm{mmHg}$, and considering a Pulsair IOP of greater than $21 \mathrm{mmHg}$ as a positive test result, the sensitivity of the Pulsair NCTs varied from $85 \%$ for the least used machine (Pulsair A) to $40 \%$ for Pulsair B. The sensitivity of Pulsair C, in which the IOPs were calculated as the mean of four readings, was $48 \%$. In comparison, Moseley et al. ${ }^{5}$ found their Pulsair NCT to have a sensitivity of $85 \%$, using as their screening criterion an IOP of greater than or equal to $21 \mathrm{mmHg}$, and using the median of five Pulsair readings. Applying this IOP criterion to our results, Pulsair $\mathrm{C}$ achieved a sensitivity of only $50 \%$. Pulsair C had previously been used in a community screening project where a requirement for referral was a Pulsair IOP (calculated as the mean of four readings) of greater than $22 \mathrm{mmHg} .{ }^{3}$ On the basis of its current performance and adopting this Pulsair IOP criterion, it is found that it could detect cases with a Goldmann IOP of greater than or equal to $24 \mathrm{mmHg}$ in the study population with a sensitivity of only $54 \%$.

The method of calculating the IOP from the individual Pulsair readings to give the best correlation with the Goldmann AT is still uncertain. The manufacturers recommend taking the mean of four consecutive readings as the IOP, although studies comparing the Pulsair and Goldmann tonometers have used different methods and conflict over which is most accurate. Moseley et al. ${ }^{5}$ found that taking the median of five consecutive readings as the IOP gave a better correlation with the Goldmann AT than the mean of four (or five) readings, although Armstrong ${ }^{6}$ found that no improvement in accuracy was achieved by excluding values deviating greater than $5 \mathrm{mmHg}$ from the mean of four readings before taking a new mean.

The Pulsair NCT features of portability, objective readings, ease of use, and freedom of infection risk make it a useful instrument especially for screening. Tuck and Crick, ${ }^{9}$ in a study of 956 opticians' premises, found that over $90 \%$ possessed a tonometer and that half of these were NCTs. In addition, optometrists using a NCT performed tonometry more frequently than those using a Goldmann AT. For such screening to be effective the continuing accuracy of the tonometer is clearly important. When used in a hospital setting the accuracy of the instrument can be checked against a calibrated Goldmann tonometer, but this is not possible for optometrists with access to only one tonometer. The other NCT commonly used by optometrists, manufactured by American Optical, can have its accuracy checked and if necessary be recalibrated on site using standardised rubber test eyes (personal communication, Birmingham Optical Group PLC). A similar electromechanical device such as the Pulsair tonometer would also be expected to suffer a drift in its accuracy with use due to wear of its components and minor trauma to the machine during use, and such a change could be unnoticed by a practitioner using the Pulsair as his only tonometer. Our results show that the accuracy of the Pulsair NCT may deteriorate with use. We suggest that there should be provision for the regular recalibration of the instrument to maintain its accuracy.

Key words: Pulsair non-contact tonometer, Goldmann applanation tonometer, Screening, Glaucoma, Intra-ocular pressure.

\section{REFERENCES}

1. Fisher JK, Watson PG, Spaeth G: A new handheld air impulse tonometer. Eye 1988, 2: 238-42.

2. Shields MB: The non-contact tonometer. Its values and limitations. Surv Ophthalmol 1980, 24: 211-19.

3. Vernon SA, Henry DJ, Carter L, Jones SJ: Screening for glaucoma in the community by non-ophthalmically trained staff using semi-automated equipment. Eye 1990, 4: 89-97.

4. Vernon SA: Non-contact tonometry in the postoperative eye. Br J Ophthalmol 1989, 73: 247-9.

5. Moseley MJ, Evans NM, Fielder AR: Comparison of a new non-contact tonometer with Goldmann applanation. Eye 1989, 3: 332-7. 
6. Armstrong TA: Evaluation of the Tono-pen and Pulsair tonometers. Am J Ophthalmol 1990, 109: 716-20.

7. Climenhaga $\mathrm{H}$, Plucinska $\mathrm{H}$ : Comparison of the Pulsair noncontact tonometer and the Goldmann applanation tonometer. Can J Ophthalmol 1989, 24: 7-9.
8. Bland JM, Altman DG: Statistical methods for assessing agreement between two methods of clinical measurement. Lancet 1986, i: $307-10$.

9. Tuck M, Crick R: Testing and referral for chronic glaucoma. Health Trends 1989, 21: 131-4. 